Review

\title{
Cytotoxic Activity of Ursolic Acid Derivatives Obtained by Isolation and Oxidative Derivatization
}

Kishor Mazumder $^{1,2}$, Katsunori Tanaka ${ }^{3}$ and Koichi Fukase ${ }^{2, *}$

1 Department of Pharmacy, University of Science and Technology Chittagong, Foy's Lake, Chittagong 4202, Bangladesh; E-Mail: k.mazumder@pharmacy.ustc.ac.bd

2

Department of Chemistry, Graduate School of Science, Osaka University, 1-1 Machikaneyama, Toyonaka, Osaka 560-0043, Japan

3 RIKEN Advanced Science Institute, 2-1 Hirosawa, Wako-shi, Saitama 351-0198, Japan; E-Mail: kotzenori@riken.jp

* Author to whom correspondence should be addressed; E-Mail: koichi@chem.sci.osaka-u.ac.jp; Tel.: +81-6-6850-5388; Fax: +81-6-6850-5419.

Received: 14 June 2013; in revised form: 22 July 2013 / Accepted: 24 July 2013 /

Published: 26 July 2013

Abstract: Structure-activity relationships of ursane-type pentacyclic triterpenes obtained from natural sources and by chemical derivatization are reviewed. Ursolic acid, corosolic acid, and a new ursane-type pentacyclic triterpene, 7,24-dihydroxyursolic acid, were isolated from the methanolic extract of the leaves of the Bangladeshi medicinal plant, Saurauja roxburghii. Derivatization of ursolic acid by oxidation with dioxoruthenium (VI) tetraphenylporphyrins was investigated. Oxidation selectivity on the terpene structure was modulated by the auxiliaries introduced on the tetraphenylporphyrin. The natural triterpenes and oxidized derivatives were tested for cytotoxicity against the C6 rat glioma and A431 human skin carcinoma cell lines. Although they have the same ursane-type pentacyclic triterpene cores, the position and numbers of hydroxyls on the terpene structures significantly affected the activity and the selectivity towards the tested cell lines.

Keywords: ursolic acid; Saurauja roxburghii; cytotoxicity; C6 rat glioma cell line; A431 human skin carcinoma cell line; dioxoruthenium(VI) tetraphenylporphyrin; biomimetic oxidation; cytochrome P450 


\section{Introduction}

Exploration of novel drugs or drug leads from Nature has been the major subject in natural product chemistry [1]. Some possible sources of natural products include plants, marine organisms, microbes and fungi. Of the approximately 250,000 higher species of plants it is estimated that only $5 \%-15 \%$ have been investigated for natural products. Only $20 \%$ of the marine organisms, which cover more than $70 \%$ of the Earth's surface have been investigated [2]. Also, research suggests that less than $1 \%$ of bacterial species and less than $5 \%$ of fungal species are currently known [3]. Therefore, it is important that natural product chemistry continue to explore these natural resources in search of new natural products.

Plants have been utilized as medicines for thousands of years. These medicines initially took the form of crude drugs such as tinctures, teas, poultices, powders, and other herbal formulations [2,3]. The specific plants to be used and the methods of application for particular ailments were passed down through oral history. Eventually information regarding medicinal plants was recorded in herbals. In more recent history, the use of plants as medicines has involved the isolation of active compounds, beginning with the isolation of morphine from opium in the early 19th century [2,4]. Drug discovery from medicinal plants led to the isolation of early drugs such as cocaine, codeine, digitoxin, and quinine, in addition to morphine, of which some are still in use [2,5,6].

Drug discovery from medicinal plants has played an especially important role in the treatment of cancer and, indeed, most new clinical applications of plant secondary metabolites and their derivatives over the last half century have been applied towards combating cancer. Of the all available anticancer drugs between 1940 and 2002, 40\% were natural products or natural product-derived, with another $8 \%$ considered natural product mimics [5-7]. Anticancer agents from plants currently in clinical use can be categorized into four main classes of compounds: vinca (or Catharanthus) alkaloids, epipodophyllotoxins, taxanes, and camptothecins (Figure 1). Vinblastine and vincristine were isolated from Catharanthus roseus (L.) G. Don (Apocynaceae) (formerly Vinca rosea L.) and have been used clinically for over 4 0 years [8]. Podophyllotoxin was isolated from the resin of Podophyllum peltatum L. (Berberidaceae) but was found to be too toxic in mice so derivatives were made, with the first clinically approved drug being etoposide [9]. Paclitaxel was originally isolated from Taxus brevifolia Nutt. (Taxaceae) and was clinically introduced to the U.S. market in the early 1990s. Camptothecin was isolated from Camptotheca acuminata Decne. (Nyssaceae) but originally showed unacceptable myelosuppression [10-12]. Interest in camptothecin was revived when it was found to act by selective inhibition of topoisomerase I, involved in cleavage and reassembly of DNA [13]. Together, the taxanes and the camptothecins accounted for approximately one-third of the global anticancer market in 2002, over 2.75 billion dollars. Numerous derivatives of all four compound classes have been synthesized, some of which are currently in clinical use. All of these natural products have led to significant biological discoveries related to their unique mechanisms of action.

Alternatively, the pentacyclic triterpenes are one group of promising secondary plant metabolites for cancer treatment. The triterpenes belonging to the lupane, oleanane or ursane groups have the potential to treat the cancer by different modes of action. Since Pisha et al. [14] reported in 1995 that betulinic acid (1) is a highly promising anticancer drug after inducing apoptosis in melanoma cell lines in vitro and in vivo (Figure 2), experimental work has focused on the apoptosis-inducing mechanisms 
of betulinic acid and other triterpenes. The antitumor effects were subsequently confirmed in a series of cancer cell lines from other origins, for example breast, colon, lung and neuroblastoma. In addition, in the last decade many studies have shown further effects that justify the expectation that triterpenes are useful to treat cancer by several modes of action.

Figure 1. Plant derived anti-cancer agents: Four main classes of natural products.

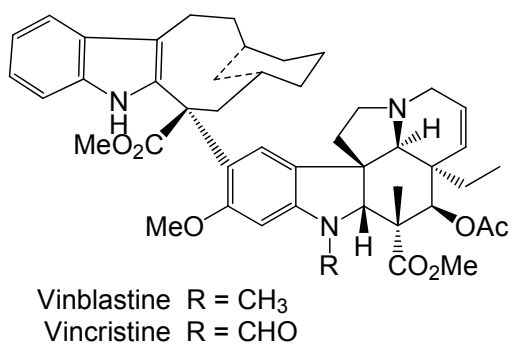

Vinca Alkaloids

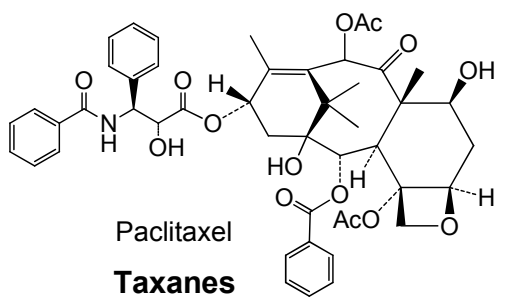

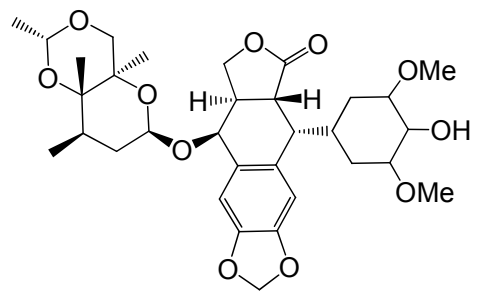

Etoposide

Phodophyllotoxins

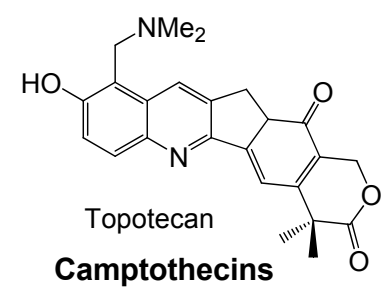

Figure 2. Structures of betulinic acid, ursane-type pentacyclic triterpenes, and derivatives.
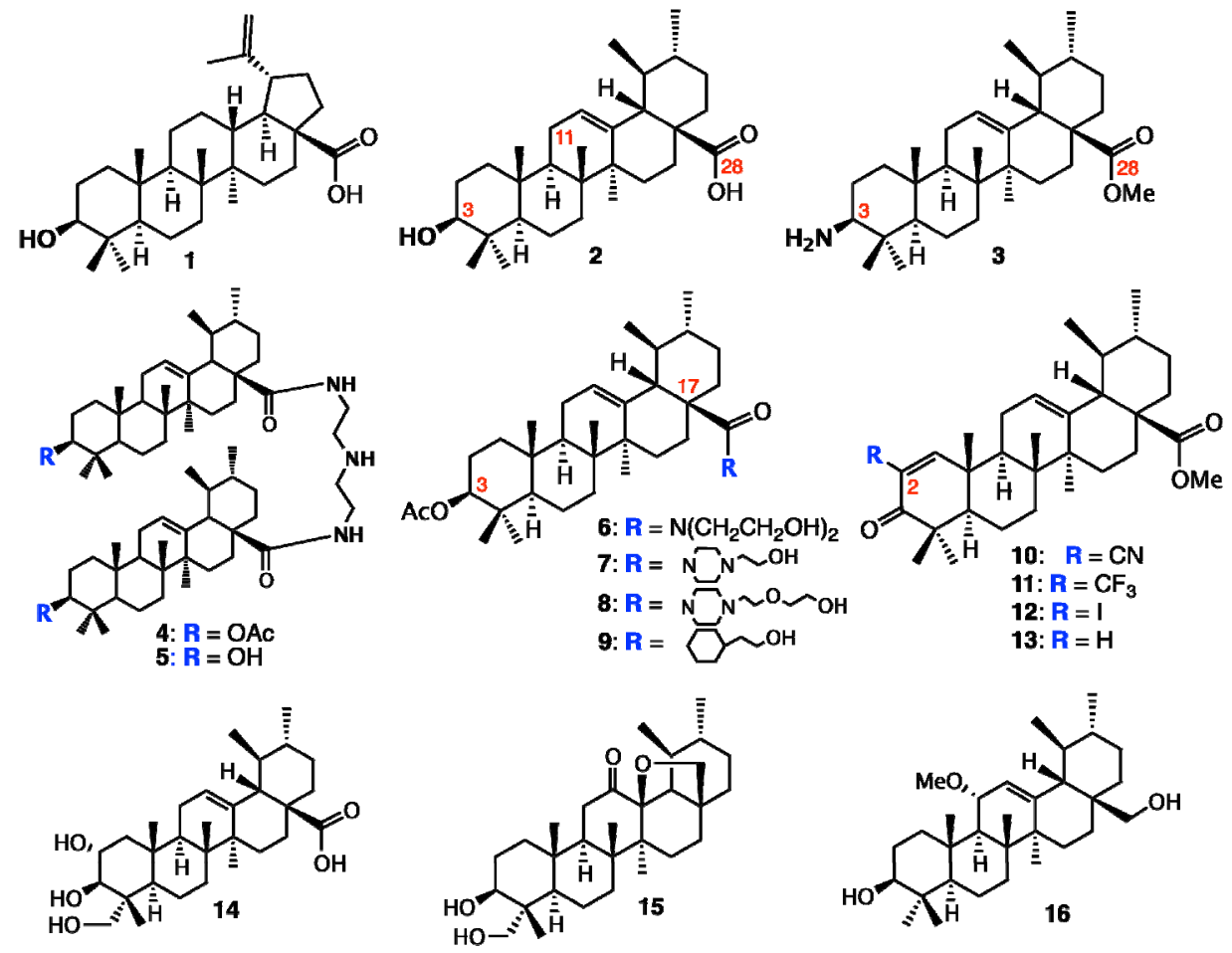

\section{Ursane-Type Natural Triterpenes from Plants}

Ursane type pentacyclic triterpenes abundantly exist in the plant kingdom. Of the ursane type

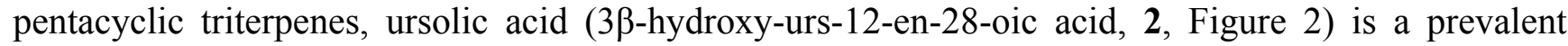


pentacyclic triterpenoid. It has been found in various plants in both aglycone and glycoside forms, and traditional uses of plants containing 2 in folk medicine are abundant. Modern studies have shown that ursolic acid possesses many biological effects, such as anti-oxidative, anti-inflammatory, antitumor, and hepato-protective activity. The diverse inflammatory effects of ursolic acid were reviewed by Ikeda et al. in 2008 [13]. This review also summarized the inhibitory activity of ursolic acid on cancer cells. Ursolic acid proved to suppress the NF- $\kappa$ B pathway via inhibition of p65 phosphorylation, thereby causing down-regulation of the expression of downstream oncogenes. Compound ursolic acid may also reduce skin tumor formation by inhibiting the binding of carcinogen to epidermal DNA or cell membrane. Furthermore, ursolic acid induces cell differentiation and apoptosis in certain cancer cell lines. Ursolic acid exhibited chemopreventive effects during the cancer initiation phase of an in vivo inhibitory assay of aberrant crypt foci (ACF), which are putative precursors of colon cancer, and increased neutral sphingomyelinase activity [15]. Ursolic acid also inhibited endogenous reverse transcriptase (RT), an enzyme involved in the control of cell proliferation and differentiation, in melanoma (A375) and anaplastic carcinoma (ARO) cell lines. Down-regulation of the expression of two cancer-related genes, c-myc and cyclin-D1, in A375 and/or ARO cells was also stimulated by ursolic acid [16].

Several attempts were undertaken for the derivatization of ursolic acid seeking to obtain analogs with improved anti-tumor activity (Figure 2). Chao-Mei Ma et al. [17] modified the C-3, C-28, C-11 positions of ursolic acid (2). Among the 23 derivatives they synthesized, $3 \beta$-amino derivative 3 was found to be 20 times more potent than the parent ursolic acid on the HL-60, Bel-7402 and HeLa cell lines. Usually, compounds with $\beta$-oriented hydrogen-bond forming groups at $\mathrm{C}-3$ exhibit more potent cytotoxicity than their $\alpha$-counterparts. Besides, dimeric compounds $\mathbf{4}$ and $\mathbf{5}$ show selective cytotoxicity against HL-60 cell lines. Similarly, Shao et al. [18] also synthesized 23 derivatives by modifying at C-3 and the C-28 positions; significant improvement of the cell growth inhibition of human embryonic lung fibroblast cells (HELF) was achieved when an acetyl group was introduced the 3-OH position, and also alkylamino and/or piperidine groups were introduced at the 17-COOH position in 6-9. Their SAR studies also showed that a polar group at either the 3-OH and/or 17-COOH positions was essential for the cytotoxic activity. Alternatively, C-2 cyano or trifluoromethyl derivatives of 1-en-3one-ursolic acid (compounds $\mathbf{1 0}$ and 11) showed higher activity than C-2 iodo- and non-substituted analogues (compounds 12 and 13) in antiproliferation assays using KU7, 253JB-V, Panc-1, and Panc-28 cancer cell lines ( $\left.\mathrm{IC}_{50}: 0.17-1.13 \mathrm{mM}\right)$ [19]. Among the natural ursane-triterpenes asiatic acid (14) was reported to significantly reduce the formation of skin tumors. Concurrently, 14 inhibited the tissue plasminogen activator (TPA), generation of NO, and expression of iNOS and COX-2, which are important factors in tumor promotion [20]. In addition, 14 induced apoptosis in PPC-1 and U-87MG

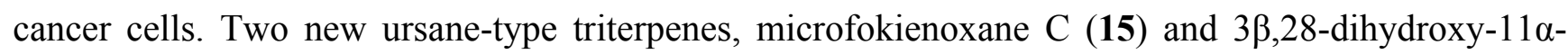
methoxyurs-12-ene (16) have recently been isolated from the leaves of Microtropis fokienensis; compound 15 showed cytotoxic activity against HepG2 and Hep3B cancer cell lines while compound 16 exhibited the activity against the HepG2 cell line [21]. Boswellic acids, containing the different type of pentacyclic core skeletons also exhibited the cytotoxic activities against several tumor cell lines of which the Structure Activity Relationship are summarized in Figure 3. 
Figure 3. Substituent effects of boswellic acid analogs on cytotoxicity.

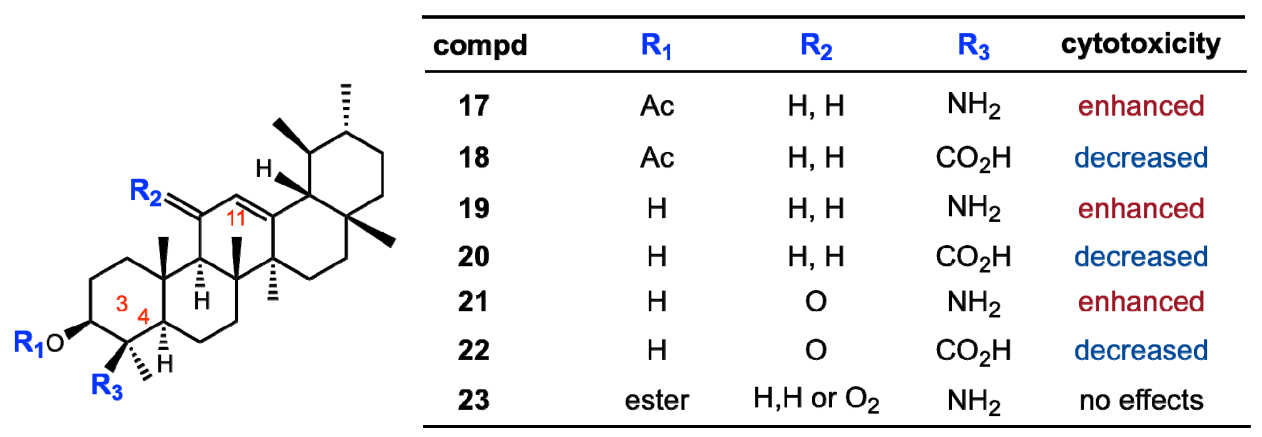

Thus, ursolic acid and its derivatives have been reported to show cytotoxicity against some cancer cell lines but have not been thoroughly explored in comparison to beutalinic acid derivatives and other lupanes. For examples, besides the derivatization of preexisting hydroxyl groups, their number and position in ursane triterpene structures, which may affect the cytotoxic activity, have not been investigated. Under such circumstances, recently Mazumder et al. [22] investigated the isolation of the biologically active compounds from the plant extracts of Saurauja roxburghii. This is an evergreen tree belonging to the family Dilleniaceae commonly found in Bangladesh, Butan, Northeast India, Nepal, Malaysia, Pakistan and Sri Lanka with various local names such as Sing krang, Sing khau, etc. Hereinafter Tanaka et al. [23] developed a ruthenium prophyrin-based catalytic oxidation procedure to obtain oxidized derivatives of ursolic acid, and additionally they investigated the cytotoxic activity against A431 and C6 cell lines both for the natural and semi-synthetic compounds. The following section reviews the isolation, structural elucidation, oxidative derivatization and evaluation of the cytotoxic activity of ursoilc acid and its derivatives.

\subsection{Isolation of Triterpene Natural Products from Leaves of Saurauja roxburghii}

Mazumder et al. [22] isolated pentacyclic triterpenes, mainly of the ursane type, from the sun-dried leaves of the plant Saurauja roxburghii, where powdered plant leaves were soaked in $\mathrm{MeOH}$ for seven days with occasional shaking and stirring (Figure 4). The whole mixture was then filtered and the filtrate was evaporated under the reduced pressure at $40-50{ }^{\circ} \mathrm{C}$ to give a gummy concentrate of the crude extract. The extract was subjected to solvent-solvent partitioning using conventional procedures. Then the chloroform fraction was subjected to the column chromatography on silica gel (sequentially eluted by $n$-hexane-chloroform (1:1), chloroform-methanol (9:1, 3:1, 1:3), and then methanol), and then subjected to the repeated reverse phase (RP)-HPLC, otherwise normal phase HPLC was used. Eventually five ursane-type triterpenes were isolated (Figure 4).

\subsection{Structural Determination of Ursane-Type Triterpenes}

As these urs-12-en-28-oic acids are widely available in the plant kingdom, their basic skeletons (see the basic structure in Figure 4) can easily be characterized by their common NMR spectroscopic features, e.g., the presence of: (1) the sharp singlet methyl protons at C-23, 24, 25, 26, and 27 and the two doublet upper field methyl protons at C-2 and C-3; (2) one olefinic proton signal for $12-\mathrm{H}$ and a characteristic doublet proton signal for $18-\mathrm{H}$ at around $2.5 \mathrm{ppm}(J=12 \mathrm{~Hz})$, along with (3) the thirty 
carbon signals in ${ }^{13} \mathrm{C}-\mathrm{NMR}$, which include two olefinic carbons for C-12 and C-13 and one down field carbonyl carbon for C-28 at around $\delta 180$. Although Mazumder et al. [22] reported five terpenoids, of these four were previously known compounds. The authors pointed out that the simple comparison of their one-dimensional NMRs with the reported spectra was not sufficient to assign the structures, due to the similarity of all their structures, hence their ${ }^{1} \mathrm{H}$ and/or ${ }^{13} \mathrm{C}$ NMR signals, i.e., only the differences in the number of hydroxyls and/or the position of the hydroxyl and the methyl substitutions in the same skeleton (see the structures in Figure 4) were distinguishable. Therefore, all two dimensional NMR experiments for each compound, such as ${ }^{1} \mathrm{H}-{ }^{1} \mathrm{H}$ COSY, HMQC, HMBC, and NOESY measurements were performed and compared with the reported data. Each structure was then determined as follows. Compound 2, i.e., ursolic acid, was obtained as a pale yellow amorphous solid. The ursane-12-en skeleton of 2 was established by the characteristic ${ }^{1} \mathrm{H}-\mathrm{NMR}$ signals of the two doublet methyl protons for $29-\mathrm{H}$ and $30-\mathrm{H}$ at $1.01(3 \mathrm{H}, \mathrm{d}, J=6.0)$ and $0.96(3 \mathrm{H}, \mathrm{d}, J=12.6)$, the $12-\mathrm{H}$ vinyl proton at $5.49(\mathrm{t})$ and the doublet methine proton (for $18-\mathrm{H})$ at $2.64(\mathrm{~d}, J=11.4 \mathrm{~Hz}$ ). Stereochemistry of the 3-hydroxyl on the A-ring was elucidated by the observation of the doublet/doublet 3-H proton signal at $3.46(J=10.8,5.4 \mathrm{~Hz})$; such coupling constants indicated the $3-\mathrm{H}$ proton was oriented as one axial/axial and one equatorial/axial orientations in the A-ring, hence the $\alpha$-proton. This substitution was further confirmed by the ${ }^{13} \mathrm{C}-\mathrm{NMR}$ signal of C-3 at $78.2 \mathrm{ppm}$ [24], and also supported by the ${ }^{1} \mathrm{H}-{ }^{1} \mathrm{H}$ COSY, HMQC, and HMBC experiments [25-27]. Compound 24, corosolic acid, was obtained as a white amorphous solid. The ursane-12-en skeleton of this terpenoid was deduced as being similar to that of ursolic acid [28,29]. Specifically, the ${ }^{13} \mathrm{C}-\mathrm{NMR}$ analysis detected the two oxygenated methane signals at 69.1 (C-2) and 83.9 (C-3), which suggested a 2,3-dihydroxyl ursolic acid structure [30]; the positions and the relative configurations of these two hydroxyls, i.e., the 2,3-dihydroxyls, was unambiguously concluded by 2D-NMR experiments such as ${ }^{1} \mathrm{H}-{ }^{1} \mathrm{H}$ COSY, HMQC and HMBC data. Compound 25, 24-hydroxyl corosolic acid, was obtained as a white amorphous solid. This natural terpene contains the ursane-12-en skeleton with the two hydroxy substitutions at the C-2 and C-3, showing very similar NMRs to those of the corosolic acid $\mathbf{2 4}$. The ${ }^{1} \mathrm{H}-\mathrm{NMR}$ showed the diastereotopic hydroxymethylene protons as two doublet protons at 3.37 and 4.01, which in turn exhibited the cross-peak correlation with a carbon signal at 66.2 in HSQC spectrum. The further analysis of NOE, HMBC and NOESY confirmed the structure as 2,3,24trihydroxyl-urs-12-en-28-oic acid. Compound 26, maslinic acid, was obtained as a white amorphous solid. The NMR data were very similar to those of the corosolic acid $\mathbf{2 4}$ except for the environment around the dimethyl groups in the E-ring; while two methyl signals in the corosolic acid $\mathbf{2 4}$ split into the doublets, they were both singlets in 26. Additionally, no COSY correlations were observed among the $29-\mathrm{H}, 19-\mathrm{H}, 20-\mathrm{H}$, and $30-\mathrm{H}$ as in $\mathbf{2 4}$. Based on DEPT analysis, the compound $\mathbf{2 6}$ should contain the gem-dimethyl substituent at the C-20 position of the E-ring, hence leading to the maslinic acid structure, a positional isomer of corosolic acid. Compound $\mathbf{2 7}$ was reported as new compound, which was obtained as an amorphous solid. IR detected the representative absorption bands for the ursane-12en structure, such as the hydroxyl $\left(3,402 \mathrm{~cm}^{-1}\right)$, carbonyl $\left(1,684 \mathrm{~cm}^{-1}\right)$, and olefinic $\left(1,562 \mathrm{~cm}^{-1}\right)$ groups. The ${ }^{1} \mathrm{H}-\mathrm{NMR},{ }^{13} \mathrm{C}-\mathrm{NMR}$, and HMBC correlation suggested the structure of 27 being very similar to the 24-hydroxyl corosolic acid 24. Thus, ${ }^{1} \mathrm{H}-\mathrm{NMR}$ detected the characteristic proton signals for the ursane-12-en skeleton, i.e., one olefinic proton at 5.22, four singlet methyl proton at $0.81,0.96$, 1.08 , and 1.13, and two doublet methyl protons at $0.88(3 \mathrm{H}, \mathrm{d}, J=6.4)$ and at $0.96(3 \mathrm{H}, \mathrm{d}, J=6.4)$. 
${ }^{13} \mathrm{C}-\mathrm{NMR}$ analysis also detected the two olefinic carbons at 126.7 and 139.7 , in addition to the six methyl signals at 17.4, 17.6, 17.7, 21.6, 23.1, and 24.1. As the case of the other ursane-12-en-type structures 2, 24, 25, the cis-fused D/E ring systems was also confirmed by the observation of the NOESY correlation between $12-\mathrm{H}$ and $18-\mathrm{H}$. The observation of the carbon signals at 65.9 (methylene carbon based on DEPT analysis), 66.9 (methine carbon), and 74.6 (methine carbon), suggested the presence of three hydroxyls on the ursane-12-en skeleton; the oxymethine carbon at C-3 (74.6) was assigned through HMBC correlations with $\mathrm{H}-23$ (1.08) and H-24 (3.63). NOE between the 3-H and axial 1-H concluded the $\beta$-orientation of the hydroxyl at $\mathrm{C}-3$. Alternatively, the oxymethylene at the $\beta$-substituted C-24 position (65.9) was assigned through the HMBC correlations with 23-H (1.08), 5-H (1.31), and 3-H (3.73), as well as the NOESY correlation with 1-H. The oxymethine at C-7 (66.9) was also assigned based on the HMBC correlations with 5-H (1.31) and 6-H (1.32); the NOESY correlation with axial 3-H and the bridgehead 27-H moreover determined the -axial orientation of 7-H (hence the $\beta$-hydroxyl at C-7). The ${ }^{1} \mathrm{H}-{ }^{1} \mathrm{H}$ COSY and HMQC experiments were further carried out to assign all proton and carbon signals in $\mathbf{2 7}$, giving rise to a new corosolic acid derivative, 3, 7, 24-trihydroxyl-urs12-en-28-oic acid. This compound further been confirmed by ESI-QTOF MS/MS fragmentation analysis [31].

Figure 4. Ursolic acid derivatives isolated from Saurauja roxburghii.
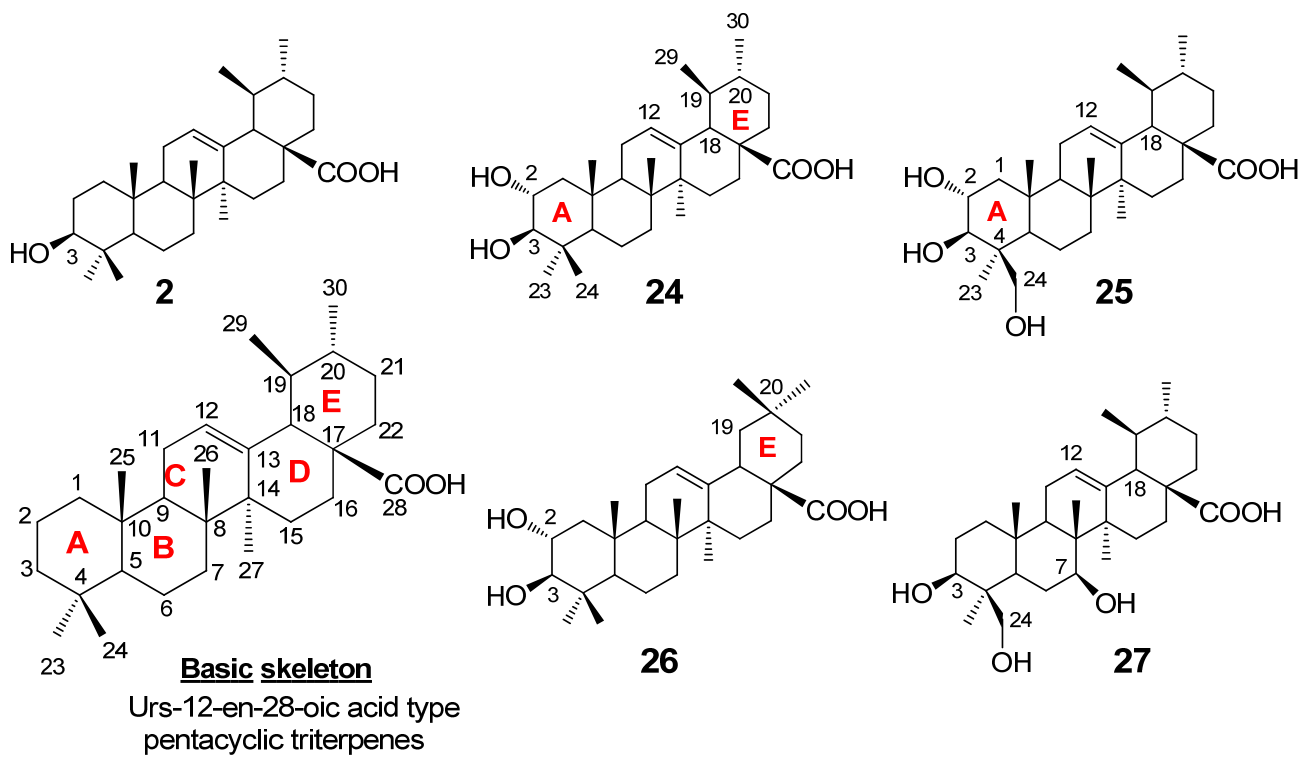

\section{Biomimetic Oxidative Derivatization of Ursolic Acid}

As described above, the hydroxylation patterns of ursane-type triterpenes significantly affects the cytotoxicity. These hydroxylated terpene metabolites are produced in many higher plants through the action of cytochrome P450 [32,33]. The resulting structural variants are responsible for the diverse range of the biological activities [34-41]. Therefore, chemical oxidation or hydroxylation of the terpenes may produce structural variants for further SAR studies. The authors envisioned that biomimetic oxidation using porphyrin derivatives, i.e., the mimic of cytochrome P450, might diversify the core-structure of ursolic acid (2) [23]. The authors also pointed out that the auxiliary used on the oxidant structures affected the chemical and site selectivities, i.e., the oxidation efficiency of the $\mathrm{C}-\mathrm{H}$, 
$\mathrm{O}-\mathrm{H}$, or olefins at the different positions of the target substrates. The following sections review the development of ' $\mathrm{Ru}$ '-porphyrin catalysts, the oxidative derivatization of ursolic acid and modulation of the cytotoxicity towards different cancer cell lines.

\subsection{Development of Auxillary-Directed 'Ru'-tetraphenylporphyrin Derivatives and Oxidative} Derivatization of Ursolic Acid

Selective oxygenation of saturated $\mathrm{C}-\mathrm{H}$ bonds has been a major challenge in synthetic chemistry as exemplified by the pioneering work of Breslow and co-workers [42-45]. Lately, the regio- and stereo-selective oxidation of hydrocarbons at the late stage of the synthesis is the common trend in natural products synthesis [46]. However, it has still remained challenging to date due to the scarcity of the reagents that can efficiently and selectively oxidize the $\mathrm{C}-\mathrm{H}$ bonds, such as those of the hydrophobic terpene skeleton. Under these circumstances, biomimetic oxidation using P450 variants and porphyrin derivatives offers an intriguing opportunity for diversifying the core-structure of terpenes [32,47-49]. In fact, the oxidation of ursolic acid derivatives by "Fe"-porphyrin has previously been examined by Konoike et al. [50].

In the present study, we expected that the chemical and site-selectivities could be affected by the auxiliary on the oxidant structures, i.e., oxidation efficiency of the $\mathrm{C}-\mathrm{H}, \mathrm{O}-\mathrm{H}$, or olefins at the different positions of the target substrates. We employed the ruthenium porphyrin derivatives $\mathbf{3 . 8 a}-\mathbf{g}$ as oxidation catalysts for the oxidation of ursolic acid 2 (Scheme 1). Previously, regio- and stereo-selective oxidation of steroids using "Ru"-porphyrin 3.8a was reported by Nagano et al. [51], though "Ru"-porphyrin have been mainly used for epoxidation of alkenes [52]. "Ru"-porphyrins 3.8c-g, which contain various chiral and non-chiral amides, were prepared from acid-functionalized tetraphenyl- porphyrin 3.8b (Scheme 1). Ruthenium was incorporated into tetraphenylporphyrins 3.7a-g by reacting with $\mathrm{Ru}_{3}(\mathrm{CO})_{12}$ in hot decalin [53], providing $\mathbf{3 . 8 a}-\mathbf{g}$ in $20 \%-30 \%$ yields. Then, an in situ oxidation protocol was used employing porphyrins 3.8a-g (Scheme 2) [23].

Scheme 1. Synthesis of substituted "Ru”-porphyrin oxidants, Ru(TPP)(CO).

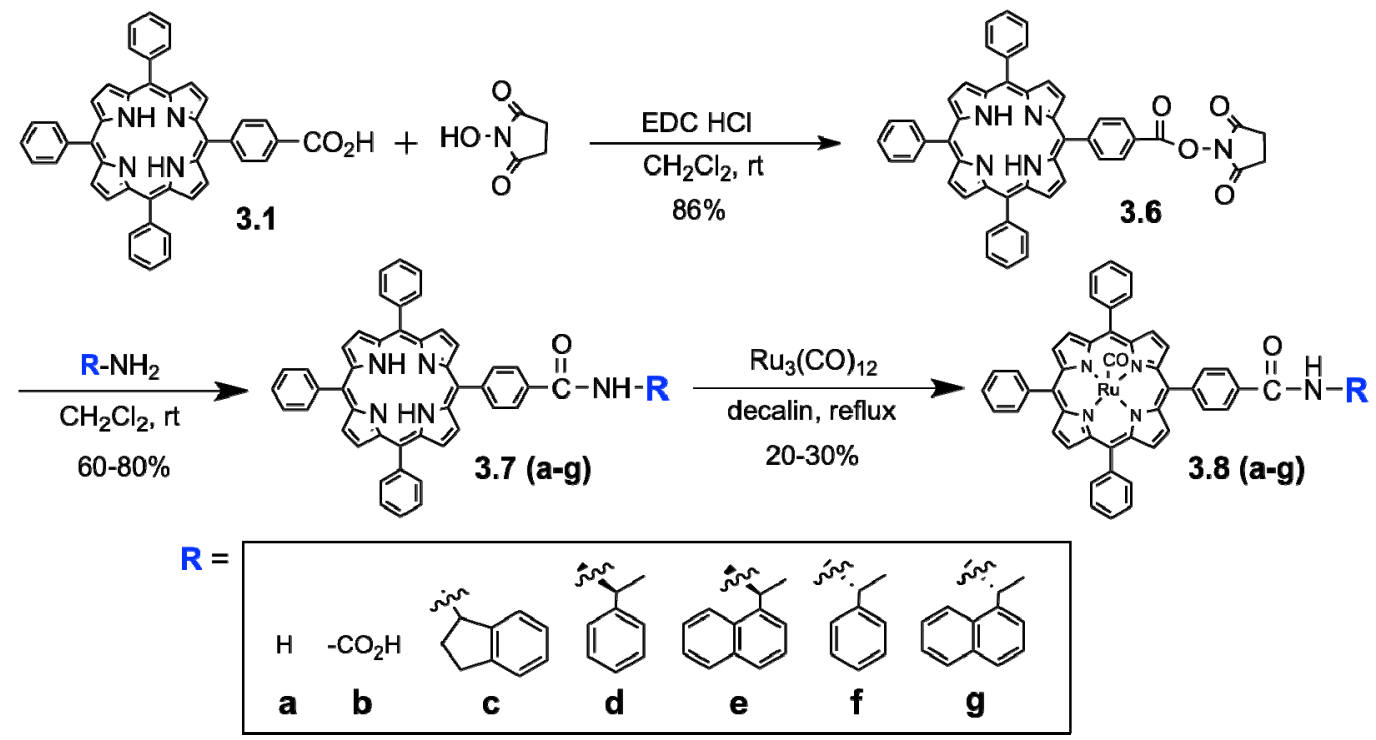


Scheme 2. Oxidation of ursolic acid by "Ru"-porphyrin oxidants.
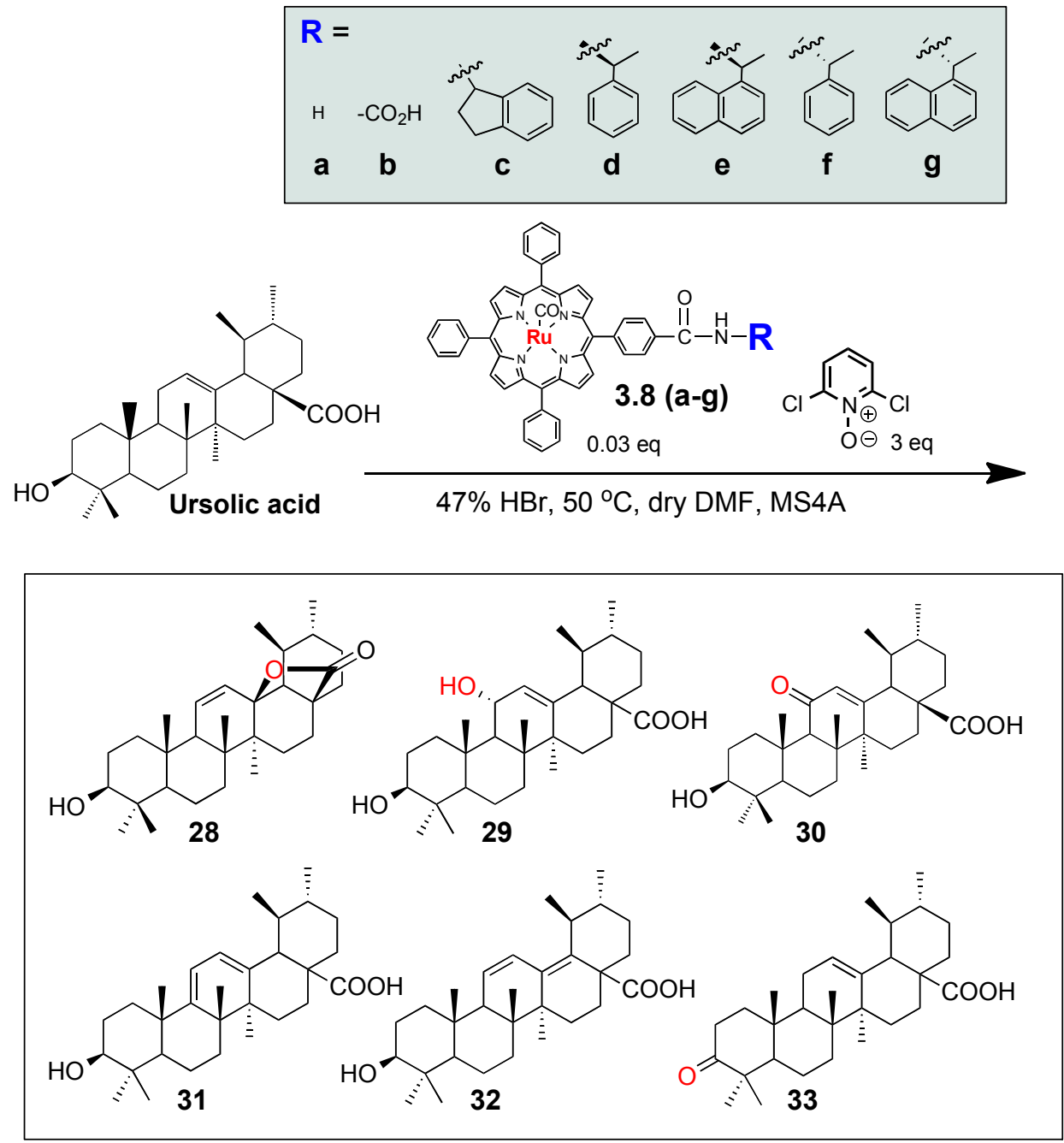

Thus, under the conditions given in Scheme 2, ursolic acid (2) was oxidized to afford variously oxidized products, including lactone 28 [54] C-11-hydroxy 29 [50,55] C-11-ketone 30 [56] dienes 31 and 32 [57] and C-3-ketone 33 [17]. All of the compounds 28-33 were known natural and/or chemically derivatized compounds. While the compound $\mathbf{3 3}$ was obtained by the oxidation of the C3-hydroxyl group of 2, the compounds 28-32 could be derived by the allylic oxidation at C-11. We also obtained the small amounts of other oxidized products, which might be derived from the oxidation of the inactivated $\mathrm{C}-\mathrm{H}$ bonds on the terpene skeleton, but enough amounts could not be obtained to determine their structures.

We observed that the distribution of the oxidized products 28-33 was clearly affected by the

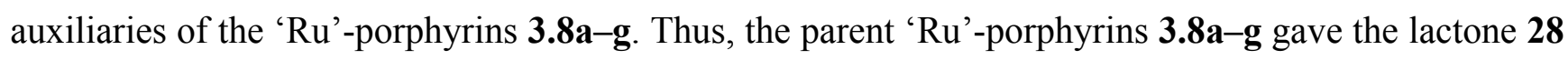
(25\%) and the $\alpha$-hydroxylated compound 29 (35\%) as two major products (Table 1), but the production of 29 was significantly decreased by the acid derivative $\mathbf{3 . 8 b}$ (4\%), instead equally producing the other derivatives 30-32 (each about 10\%); the introduction of the acid group on the metalloporphyrin might cause the interaction with the substrate $\mathbf{2}$, for example, with the carboxylic acid or the hydroxyl groups in $\mathbf{2}$, hence altering the oxidation selectivity. On the other hand, while the $(R)$-isomers 3.8d and 3.8e gave the $\alpha$-hydroxylated 29 as the major product (entries 4 and 5), the 
reactivity of the corresponding $(S$ )-oxidants $\mathbf{3 . 8 f}$ and $\mathbf{3 . 8 g}$ was significantly reduced (entries 6 and 7). For both cases, the oxidation efficiency was retarded by using the sterically more demanding 1-naphthyl derivatives 3.8e and $\mathbf{3 . 8 g}$ (the starting compound $\mathbf{2}$ was recovered in $50 \%$ and $90 \%$ yield, respectively). Meanwhile, the ketone 33 was solely obtained when the indane derivatives 3.8c was used (entry 3) [23]. This is the first observation that the auxiliaries on metalloporphyrin-based oxidants 3.8a-g gave profound effects on the oxidation reactivity and selectivity, and even small functional groups on the side chains of the tetraphenylporphyrins, i.e., acid, amides, or chirality, could recognize the triterpene structure 2, and exhibited matched and/or mismatched combinations for the dioxoruthenium-catalyzed oxidation.

Table 1. Distribution of oxidized products by "Ru"-porphyrins.

\begin{tabular}{ccccccccc}
\hline \multirow{2}{*}{ Entry } & $\begin{array}{c}\text { Porphyrin } \\
\text { catalyst }\end{array}$ & \multicolumn{7}{c}{ Product yields (\%) } \\
\cline { 2 - 8 } & $\mathbf{2}$ (recovery) & $\mathbf{2 8}$ & $\mathbf{2 9}$ & $\mathbf{3 0}$ & $\mathbf{3 1}$ & $\mathbf{3 2}$ & $\mathbf{3 3}$ \\
\hline 1 & $\mathbf{3 . 8 a}$ & 25 & 25 & 35 & 5 & ND & ND & ND \\
2 & $\mathbf{3 . 8 b}$ & 35 & 35 & 4 & 8 & 10 & 8 & ND \\
3 & $\mathbf{3 . 8 c}$ & 80 & ND & 5 & 5 & ND & ND & 10 \\
4 & $\mathbf{3 . 8 d}$ & ND & ND & 70 & 5 & ND & ND & ND \\
5 & $\mathbf{3 . 8 e}$ & 50 & ND & 30 & 10 & ND & ND & ND \\
6 & $\mathbf{3 . 8 f}$ & 75 & ND & 5 & 5 & ND & ND & ND \\
7 & $\mathbf{3 . 8 g}$ & 90 & ND & 10 & ND & ND & ND & ND
\end{tabular}

\section{Evaluation of Cytotoxic Activity towards Tumor Cell Lines}

We tested cytotoxicity of 2, 24-27 against two tumor cell lines, i.e., the human epidermoid carcinoma cell line, A431 and the rat glioma cell line, C6 [22]. The compounds 2, 24-27 were dissolved in 100\% ethanol and then diluted with Dulbecco's Modified Eagle's Medium (DMEM) as the working solutions which were added to the cells with a final volume of $0.2 \mathrm{~mL}$ (final concentration of 10-100 $\mu \mathrm{M}$ ) and cultured over $0,3 \mathrm{~h}, 6 \mathrm{~h}, 12 \mathrm{~h}, 24 \mathrm{~h}$ and $48 \mathrm{~h}$, respectively [58]. The index of cell damage was adopted with the vacuolar degeneration and necrosis. We found that the ursolic acid (2) exhibited the cytotoxicity against C6 rat glioma at the concentrations of 10-100 $\mu \mathrm{M}$, while this terpenoid did not show any activity towards the A431 carcinoma (Table 2). Meanwhile, corosolic acid (24) showed cytotoxicity against the both cell lines (Table 2). The cytotoxicity of corosolic acid to C6 glioma and A431 carcinoma had not been previously reported, though various biological activities of corosolic acid have been known [59]. Interestingly, the structural difference between ursolic acid (2) and corosolic acid (24) was the additional hydroxyl group at the C-2 in $\mathbf{2 4}$ (Figure 4). Namely, a single hydroxyl group on the A-ring of the ursane-12-en skeleton makes the cytotoxic activity selective against the C6 cell line. On the other hand, no cytotoxic activity could be observed for the other compounds 25-27 at the 10-100 $\mu \mathrm{M}$ concentration range (Table 2). 
Table 2. Cytotoxicity of compounds 2, 24-33 against two tumor cell lines, A431 human epidermoid carcinoma and C6 rat glioma. Cells were treated with $10 \mu \mathrm{M}$ of the compound at $37{ }^{\circ} \mathrm{C}$. "+" stands for positive and "-" stands for negative responses on morphological changes after $24 \mathrm{~h}$.

\begin{tabular}{ccc}
\hline Compound & $\begin{array}{c}\text { A431 human } \\
\text { epidermoid carcinoma }\end{array}$ & C6 rat glioma \\
\hline $\mathbf{2}$ & - & + \\
$\mathbf{2 4}$ & + & + \\
$\mathbf{2 5}$ & - & - \\
$\mathbf{2 6}$ & - & - \\
$\mathbf{2 7}$ & - & - \\
$\mathbf{2 8}$ & + & + \\
$\mathbf{2 9}$ & - & - \\
$\mathbf{3 0}$ & - & - \\
$\mathbf{3 1}$ & - & - \\
$\mathbf{3 2}$ & - & - \\
$\mathbf{3 3}$ & - & - \\
\hline
\end{tabular}

Again, the simple modification of the cytotoxic $\mathbf{2 4}$ by introducing the hydroxyl group at C-24 (giving 25) or by shifting the C-19 methyl to the C-20 (maslinic acid 26), made the compounds inactive (Figure 4). These results clearly showed the importance of the position and numbers of hydroxyls or the methyl groups on the triterpene structure for the cytotoxic activity. It is further noted that the maslinic acid (26) is reported to show the cytotoxicity against HT29 human colon-cancer cells [31]; hence maslinic acid should exhibit selective activity to the HT29. Alternatively, asiatic acid ( $2 \alpha, 2 \beta, 23$-trihydroxy-urs-12-en-28-oic acid), the epimer of $\mathbf{2 5}$, is a strong cytotoxic natural product against some cancel cells, such as the human glioblastoma cell lines U-87, human breast cancer cell lines MCF-7 (ATCC HTB-22), MDA-MD-231 (ATCC HTB-26), and the human hepatoma cell Hep G2 [24,60,61]. Thus, the tunable cytotoxicity and selectivity to the cell lines by the slight modification of their structures, i.e., functional group substitutions and/or stereochemistry, make these triterpene natural products promising candidates for drug development and/or for tools for investigating the mode of action. On the other hand, for chemically oxidized compounds 28-33, cytotoxicity was also examined as the same way as described for compounds 2, 24-27. It was observed that only the lactone $\mathbf{2 8}$ had cytotoxic activity against both the A431 and C6 tumor cell lines; therefore we can conclude that the oxidation at the $\mathrm{C}-11$ and $\mathrm{C}-13$ positions of ursolic acid (2), gave ursolic acid an additional cytotoxic activity against A431 tumor cell. Thus, the authors observed that the cytotoxic activity and the tumor selectivity of the natural and the chemically oxidized ursolic acids are sensitively modulated by simply modulating the oxidation states on the core terpene structure. 


\section{Conclusions}

Natural products are the most consistently successful sources of biologically diverse compounds, and especially, plants provide a large bank of rich, complex, and highly varied structures. Many higher plants contain densely oxidized terpene metabolites, i.e., with carboxyl or hydroxyl groups, of which structural variants exhibit a diverse range of activities. Alternatively, the core terpene structures could also be derivatized by the chemical oxidation in pursuit of enhancing the activity and/or modulating the target selectivity, i.e., against a specific tumor cell line. We investigated the isolation of the natural products from the extracts of the Bangladeshi medicinal plant, Saurauja roxburghii, a higher plant indigenous to south East Asia and some parts of North America. By using conventional extraction procedures, we isolated the five ursane-type pentacyclic triterpenes. The structures of these five compounds were unambiguously determined by extensive NMR and MS analyses, and also by comparisons with the literature data, if available. Then these natural triterpenes were tested for cytotoxicity against the C6 rat glioma and A431 human skin carcinoma cell lines. Very interestingly, despite the fact that these five compounds have the same ursane-type pentacyclic triterpene core structures, only ursolic acid (2) and corosolic acid (24) showed cytotoxicity at $10 \mu \mathrm{M}$ concentrations. Furthermore, while the corosolic acid showed the cytotoxicity against both cell lines, ursolic acid exhibited selective cytotoxicity against the C6 glioma cell. These results clearly show that the position and numbers of hydroxyls on the terpene structure affect the activity and selectivity to the cancer cell lines. Inspired by these results, our group sought to diversify the hydrophobic ursane-type triterpene ursolic acid, for further SAR studies, by applying chemical oxidation using "Ru"-porphyrins. The newly developed auxiliary catalyzed 'Ru'-tetraphenylporphyrins chemical oxidation system could produce oxidized ursolic acid derivatives could give a new direction in designing the porphyrin-based reagents as well as other oxidants. It is noted that the chemically oxidized products $\mathbf{2 8 - 3 3}$ were all naturally occurring compounds, but were difficult to isolate from the $S$. roxburghii in previous investigations, thus the chemical protocol can be complementary to the isolation of natural products.

\section{Conflict of Interest}

The authors declare no conflict of interest.

\section{References and Notes}

1. Knowles, J.; Gromo, G. Target selection in drug discovery. Nat. Rev. Drug Discov. 2003, 2, 63-69.

2. Samuelsson, G. Drugs of Natural Origin: a Textbook of Pharmacognosy, 5th ed.; Swedish Pharmaceutical Press: Stockholm, Sweden, 2004; pp. 154-155.

3. Balick, M.J.; Cox, P.A. Plants, People, and Culture: the Science of Ethnobotany, 1st ed.; Freeman and Co: Scientific American Library, New York, NY, USA, 1997; pp. 8-9.

4. Kinghorn, A.D. Pharmacognosy in the 21st century. J. Pharm. Pharmacol. 2001, 53, 135-148.

5. Newman, D.J.; Cragg, G.M.; Snader, K.M. The influence of natural products upon drug discovery. Nat. Prod. Rep. 2000, 17, 215-234. 
6. Butler, M.S. The role of natural product chemistry in drug discovery. J. Nat. Prod. 2004, 67, 2141-2153.

7. Newman, D.J.; Cragg, G.M.; Snader, K.M. Natural products as sources of new drugs over the period 1981-2002. J. Nat. Prod. 2003, 66, 1022-1037.

8. van der Heijden, R.; Jacobs, D.I.; Snoeijer, W.; Hallard, D.; Verpoorte, R. The Catharanthus alkaloids: Pharmacognosy and biotechnology. Curr. Med. Chem. 2004, 11, 607-628.

9. Gordaliza, M.; Garcia, P.A.; Corral, J.M.; Castro, M.A.; Gomez-Zurita, M.A. Podophyllotoxin: Distribution, sources, applications and new cytotoxic derivatives. Toxicon 2004, 44, 441-459.

10. Wall, M.E.; Wani, M.C. Camptothecin and taxol: From discovery to clinic. J. Ethnopharmacol. 1996, 51, 239-253.

11. Oberlies, N.H.; Kroll, D.J. Camptothecin and taxol: Historic achievements in natural products research. J. Nat. Prod. 2004, 67, 129-135.

12. Cragg, G.M.; D.J. Newman, D.J. A tale of two tumor targets: Topoisomerase I and tubulin. The Wall and Wani contribution to cancer chemotherapy. J. Nat. Prod. 2004, 67, 232-244.

13. Ikeda, Y.; Murakami, A.; H. Ohigashi, H. Ursolic acid: An anti- and pro-inflammatory triterpenoid. Mol. Nutr. Food Res. 2008, 52, 26-42.

14. Pisha, E.; Chai, H.; Lee, I.S.; Chagwedera, T.E.; Farnsworth, N.R.; Cordell, G.A.; Beecher, C.W.; Fong, H.H.; Kinghorn, A.D.; Brown, D.M. Discovery of betulinic acid as a selective inhibitor of human melanoma that functions by induction of apoptosis. Nat. Med. 1995, 1, 1046-1051.

15. Andersson, D.; Cheng, Y.; Duan, R.D. Ursolic acid inhibits the formation of aberrant crypt foci and affects colonic sphingomyelin hydrolyzing enzymes in azoxymethane-treated rats. J. Cancer Res. Clin. Oncol. 2008, 134, 101-107.

16. Bonaccorsi, I.; Altieri, F.; Sciamanna, I.; Oricchio, E.; Grillo, C.; Contartese, G.; Galati, E.M. Endogenous reverse transcriptase as a mediator of ursolic acid's antiproliferative and differentiating effects in human cancer cell lines. Cancer Lett. 2008, 263, 130-139.

17. Ma, C.-M.; Cai, S.-Q.; Cui, J.-R.; Wang, R.-Q.; Tu, P.-F.; Hattori, M.; Daneshtalab, M. The cytotoxic activity of ursolic acid derivatives. Eur. J. Med. Chem. 2005, 40, 582-589.

18. Shao, J.-W.; Dai, Y.-C.; Xue, J.-P.; Wang, Ji.-C.; Lin, F.-P.; Guo, Y.-H. In vitro and in vivo anticancer activity evaluation of ursolic acid derivatives. Eur. J. Med. Chem. 2011, 46, 2652-2661.

19. Chadalapaka, G.; Jutooru, I.; McAlees, A.; Stefanac, T.; Safe, S. Structure-dependent inhibition of bladder and pancreatic cancer cell growth by 2-substituted glycyrrhetinic and ursolic acid derivatives. Bioorg. Med. Chem. Lett. 2008, 18, 2633-2639.

20. Park, B.C.; Paek, S.H.; Lee, Y.S.; Kim, S.J.; Lee, E.S.; Choi, H.G.; Yong, C.S.; Kim, J.A. Inhibitory effects of asiatic acid on 7, 12-dimethylbenz[/]anthracene and 12-O-tetradecanoylphorbol 13-acetate-induced tumor promotion in mice. Biol. Pharm. Bull. 2007, 30, 176-179.

21. Chen, I.H.; Chang, F.R.; Wu, C.C.; Chen, S.L.; Hsieh, P.W.; Yen, H.F.; Du, Y.C.; Wu, Y.C. Cytotoxic triterpenoids from the leaves of Microtropis fokienensis. J. Nat. Prod. 2006, 69, 1543-1546.

22. Mazumder, K.; Swiu, E.R.O.; Nozaki, S.; Watanabe, Y.; Tanaka, K.; Fukase, K. Ursolic Acid Derivatives from Bangladeshi medicinal plant, Sarauja roxburghii: Isolation and cytotoxic activity against A431 and C6 glioma cell lines. Phytochem. Lett. 2011, 4, 287-291. 
23. Tanaka, K.; Mazumder, K.; Siwu, E.R.O.; Nozaki, S.; Watanabe, Y.; Fukase, K. Auxiliarydirected oxidation of ursolic acid by "Ru"-porphyrins: Chemical modulation of cytotoxicity against tumor cell lines. Tetrahedron Lett. 2012, 53, 1756-1759.

24. Hsu, Y.-L.; Kuo, P.L.; Lin, L.T.; Lin, C.C. Asiatic acid, a triterpene, induces apoptosis and cell cycle arrest through activation of extracellular signal-regulated kinase and p38 mitogen-activated protein kinase pathways in human breast cancer cells. J. Phamacol. Exp. Ther. 2004, 313, 333-344.

25. Seo, S.; Tomita, Y.; Tori, K. Carbon-13 NMR spectra of urs-12enes and application of structural assignments of components of Isodon japonicus tissue cultures. Tetrahedron Lett. 1975, 16, 7-10.

26. Reher, G.; Budensisky, M. Triterpenoids from plants of Sanguisorbae. Photochemistry 1992, 31, 3909-3914.

27. Inada, A.; Kobayashi, M.; Murata, H.; Nakanishi, T. Two new triterpenoid glycosides from leaves of Ilex chinensis SIMS. Chem. Pharm. Bull. 1987, 35, 841-842.

28. Kojima, H.; Ogura, H. Configurational studies on hydroxyl groups at C-2, 3 and C-23 of oleanene and ursene-type trirerpenes by NMR spectroscopy. Phytochemistry 1989, 28, 1703-1989.

29. Bilia, A.R.; Mendezb, J.; Morellia, I. Phytochemical investigations of Licania genus. Flavonoids and triterpenoids from Licania carii. Pharm. Acta Helv. 1996, 71, 191-197.

30. Lee, C.K. Ursane triterpenoids from leaves of Melaleuca leucadendron. Phytochemistry 1998, 49, 1119-1122.

31. Reyes-Zurita, F.J.; Rufino-Palomares, E.E.; Lupiáñez, J.A.; Cascante, M. Maslinic acid, a natural triterpene from Olea europaea L., induces apoptosis in HT29 human colon-cancer cells via the mitochondrial apoptotic pathway. Cancer Lett. 2009, 273, 44-54.

32. Murahashi, S.-I.; Zhang, D. Ruthenium catalyzed biomimetic oxidation in organic synthesis inspired by cytochrome P-450. Chem. Soc. Rev. 2008, 37, 1490-1501.

33. P450-Mediated oxidation of ursolic acid derivatives, see: Sivakumar, G.; Vail, D.R.; Nair, V.; Bolivar, F.M.; Lay, J.O. Corosolic acid the future anti-diabetic drug? Biotechnol. J. 2009, 4, 1704-1711.

34. Patocka, J.J. Biologically active pentacyclic triterpenes and their current medicine signification. Appl. Biomed. 2003, 1, 7-12.

35. Ma, C.M.; Nakamura, N.; Hattori, M.; Kakuda, H.; Qiao, J.C.; Yu, H.L.J. Inhibitory effects on HIV-1 protease of constituents from the wood of Xanthoceras sorbifolia. Nat. Prod. 2000, 63, 238-242.

36. Saraswat, B.; Visen, P.K.; Agarwal, D.P. Ursolic acid isolated from Eucalyptus tereticornis protects against ethanol toxicity in isolated rat hepatocytes. Phytother. Res. 2000, 14, 163-166.

37. Chattopadhyay, D.; Arenachalam, G.; Mandal, A. B.; Sur, T. K.; Mandal, S. C.; Bhattacharya, S. K. Antimicrobial and anti-inflammatory activity of folklore: Mallotus peltatus leaf extract. J. Ethnopharmacol. 2002, 82, 229-237.

38. Li, J.; Guo, W.J.; Yang, Q.Y. Effects of ursolic acid and oleanolic acid on human colon carcinoma cell line HCT15. World J. Gastroenterol. 2002, 8, 493-495.

39. Anderson, D.; Liu, J.J.; Nilsson, A. Ursolic acid inhibits proliferation and stimulates apoptosis in HT29 cells following activation of alkaline sphingomyelinase. Anticancer Res. 2003, 23, $3317-3322$. 
40. Choi, Y.H.; Baek, J.H.; Yoo, M.A.; Chung, H.Y.; Kim, N.D.; Kim, K.W. Induction of apoptosis by ursolic acid through activation of caspases and down-regulation of c-IAPs in human prostate epithelial cells. J. Oncol. 2000, 17, 565-570.

41. Laszczyk, M.N. Pentacyclic triterpenes of the lupane, oleanane and ursane group as tools in cancer therapy. Planta Med. 2009, 15, 1549-1560.

42. Breslow, R.; Baldwin, S.; Flechtner, T.; Kalicky, P.; Liu, S.; Washburn, W. Remote oxidation of steroids by photolysis of attached benzophenone groups. J. Am. Chem. Soc. 1973, 95, 3251-3262.

43. Das, S.; Incarvito, C.D.; Crabtree, R.H.; Brudvig, G.W. Molecular recognition in the selective oxygenation of saturated C-H bonds by a dimanganese catalyst. Science 2006, 312, 1941-1943.

44. Chen, M.S.; White, C.M. A Predictably Selective Aliphatic C-H Oxidation Reaction for Complex Molecule Synthesis. Science 2007, 318, 783-787.

45. Murahashi, S.-I. Development of biomimetic catalytic oxidation methods and non-salt methods using transition metal-based acid and base amphiphilic catalysts. Proc. Jpn. Acad. Ser. B Phys. Biol. Sci. 2011, 87, 242-253.

46. Representative example, see: Chen, K.; Baran, P.S. Total synthesis of eudesmane terpenes by site-selective C-H oxidations. Nature 2009, 459, 824-828.

47. Zhang, K; Damaty, E.1.S.; Fasan, R. P450 fingerprinting method for rapid discovery of terpene hydroxylating P450 catalysts with diversified regioselectivity. J. Am. Chem. Soc. 2011, 133, 3242-3245.

48. Costas, M. Selective C-H oxidation catalyzed by metalloporphyrins. Coord. Chem. Rev. 2011, $255,2912-2932$.

49. Ogawa, S.; Wakatsuki, Y.; Makino, M.; Fujimoto, Y.; Yasukawa, K.; Kikuchi, T.; Ukiya, M.; Akihisa, T.; Iida, T. Oxyfunctionalization of unactivated $\mathrm{C}-\mathrm{H}$ bonds in triterpenoids with tert-butylhydroperoxide catalyzed by meso-5,10,15,20-tetramesitylporphyrinate osmium(II) carbonyl complex. Chem. Phys. Lipids 2010, 163, 165-171.

50. Konoike, T.; Araki, Y.; Kanda, Y. A novel allylic hydroxylation of sterically hindered olefins by Fe-porphyrin-catalyzed mCPBA oxidation. Tetrahedron Lett. 1999, 40, 6971-6974.

51. Shingaki, T.; Miura, K.; Higuchi, T.; Hirobe, M.; Nagano, T. Regio- and stereo-selective oxidation of steroids using 2,6-dichloropyridine N-oxide catalysed by rutheniumporphyrins. Chem. Commun. 1997, 861-862.

52. Che, C.-M.; Huang, J.-S. Metalloporphyrin-based oxidation systems: From biomimetic reactions to application in organic synthesis. Chem. Commun. 2009, 27, 3996-4015.

53. Rillema, D.P.; Nagle, J.K.; Barringer, L.F.; Meyer, T.J. Redox properties of metalloporphyrin excited states, lifetimes, and related properties of a series of para-substituted tetraphenylporphyrin carbonyl complexes of ruthenium(II). J. Am. Chem. Soc. 1981, 103, 56-62.

54. Tkachev, A.V.; Denisov, A.Y.; Gatilov, Y.V.; Bagryanskaya, I.Y.; Shevtsov, S.A.; Rybalova, T.V. Acetic acid oxidation of ursolic acid and related compounds. Tetrahedron 1994, 50, 11459-11488.

55. Pereira, S.I.; Freire, C.S.R.; Neto, C.P.; Silvestre, A.J.D.; Silva, A.M.S. Chemical composition of the epicuticular wax from the fruits of Eucalyptus globulus. Phytochem. Anal. 2005, 16, 364-369.

56. Syamasundar, K.V.; Mallavarapu, G.R.; Krishna, M. Triterpenoids of the resin of Bursera delpechiana. Phytochemistry 1991, 30, 362-363. 
57. Luis, J.G.; Andres, L.S. New ursane type triterpenes from Salvia mellifera greene. Nat. Prod. Lett. 1999, 13, 187-194.

58. Li, Y.; Matsuda, H.; Yoshikawa, M. Effects of oleanolic acid glycosides on gastrointestinal transit and ileus in mice. Bioorg. Med. Chem. 1999, 7, 1201-1205.

59. Wen, X.; Xia, J.; Cheng, K.; Zhang, L.; Zhang, P.; Liu, J.; Zhang, L.; Ni, P.; Sun, H. Pentacyclic triterpenes. Part 5: Synthesis and SAR study of corosolic acid derivatives as inhibitors of glycogen phosphorylases. Bioorg. Med. Chem. Lett. 2007, 17, 5777-5782.

60. Lee, Y.S.; Jin, D.Q.; Kwon, E.J.; Park, S.H.; Lee, E.S.; Jeong, T.C.; Nam, D.H.; Huh, K.; Kim, J.A. Asiatic acid, a triterpene, induces apoptosis through intracellular $\mathrm{Ca}^{2+}$ release and enhanced expression of p53 in HepG2 human hepatoma cells. Cancer Lett. 2002, 186, 83-91.

61. Cho, C.W.; Choi, D.S.; Cardone, M.H.; Kim, C.W.; Sinskey, A.J.; Rha, C. Glioblastoma cell death induced by asiatic acid. Cell Biol. Toxicol. 2006, 22, 393-408.

Sample Availability: Not available.

(C) 2013 by the authors; licensee MDPI, Basel, Switzerland. This article is an open access article distributed under the terms and conditions of the Creative Commons Attribution license (http://creativecommons.org/licenses/by/3.0/). 